\title{
LUT
}

University

\section{Mitigating noncirculating bearing currents by a correct stator magnetic circuit and winding design}

Vostrov Konstantin, Pyrhönen Juha, Niemelä Markku, Ahola Jero, Lindh Pia

This is a Author's accepted manuscript (AAM) version of a publication

published by IEEE

in IEEE Transactions on Industrial Electronics

DOI: $\quad 10.1109 /$ TIE.2020.2984455

Copyright of the original publication: (C) 2020 IEEE

Please cite the publication as follows:

K. Vostrov, J. Pyrhonen, M. Niemelä, J. Ahola and P. Lindh, "Mitigating noncirculating bearing currents by a correct stator magnetic circuit and winding design," in IEEE Transactions on Industrial Electronics.

(C) 2020 IEEE. Personal use of this material is permitted. Permission from IEEE must be obtained for all other uses, in any current or future media, including reprinting/republishing this material for advertising or promotional purposes, creating new collective works, for resale or redistribution to servers or lists, or reuse of any copyrighted component of this work in other works.

This is a parallel published version of an original publication. This version can differ from the original published article. 


\title{
Mitigating noncirculating bearing currents by a correct stator magnetic circuit and winding design
}

\author{
K. Vostrov, J. Pyrhönen, SM, IEEE, M. Niemelä, J. Ahola, P. Lindh, SM, IEEE
}

\begin{abstract}
Different mechanisms by which bearing currents flow inside the electrical machine are well studied. In contrast, investigation and development of different techniques to mitigate these currents remain a field for improvement, and the final common solution to the problem has not been provided yet. In pursuit of addressing the problem, this paper deals with noncirculating (or capacitive) bearing currents. The circuit mechanism of capacitive currents is explained in brief, and an approach for their mitigation is introduced. The paper studies the influence of the stator winding and the slot geometry and presents different geometries to modify the motor to reduce the capacitive bearing currents. The effectiveness of the proposed mitigation technique is shown by finite element-based modeling and verified by laboratory tests with different induction motor designs, where the winding and magnetic circuit geometries are varied. The technique can be used, in particular, for the mitigation of noncirculating currents, but it also offers potential for further research.
\end{abstract}

Index Terms-Ball bearings, electrical discharge machining bearing currents, electrical machines, finite element analysis, induction machines, variable speed drives.

\section{INTRODUCTION}

$\mathrm{E}$ LECTRICAL drives play a key role in most technological processes. Being an important mechanical power unit in industrial, transportation, and civil applications, electrical drive systems determine the overall efficiency and reliability of the entire technological process. Modern electrical drives are sophisticated and can meet the requirements of accurate speed and torque adjustment. As the reliability of power electronic components has increased and their price decreased, induction motors fed by frequency converters have become a widespread and common solution for a wide range of applications. Such a solution combines the reliability and constructive simplicity of induction motors with a wide range

Manuscript received November 28, 2019; revised February 13, 2020; accepted March 17, 2020. This work was supported by the Finnish Cultural Foundation.

K. Vostrov, J. J. Pyrhönen, M. Niemelä, J. Ahola and P. M. Lindh are with LUT School of Energy Systems, LUT University, PO Box 20, 53851, Lappeenranta, Finland (e-mails: konstantin.vostrov@student.lut.fi, juha.pyrhonen@lut.fi, markku.niemela@lut.fi, jero.ahola@lut.fi and pia.lindh@lut.fi). of speed and torque variations by means of different control algorithms. However, drive systems of this kind have brought a new problem, bearing currents, which are a parasitic and destructive phenomenon. To the authors' knowledge, the phenomenon has not been thoroughly investigated yet. Different approaches to bearing current suppression have been suggested, but there is still no universal and cost-effective method available [1].

The history of bearing current problems starts from the times of the first electrical machines. In previous studies, the origin of bearing currents was determined to be the nonideal asymmetrical geometry of the motor. The bearing currents caused by the machine geometry are also called "classical" bearing currents. Since the 1980 s when the development of power electronics led to the introduction of frequency converters into electrical drive systems, the bearing current problem has reached a new level. Although manufacturing of electrical machines has become more precise and the role of "classical" bearing currents has become less significant, a new source of parasitic phenomena has occurred. The commonmode voltage and the high $\mathrm{d} u / \mathrm{d} t$ of the common-mode voltage in the power supply, caused by the frequency converter operations, induce a voltage across the bearings. Thus, in the modern literature, the bearing currents are usually considered to be due to the asymmetrical motor geometry and the frequency converter operation.

Based on the modern understanding of the parasitic and bearing current phenomena, these currents are divided into several groups depending on the current path inside the electrical drive system, as shown in Fig. 1 [2]. The parasitic currents are grouped as follows: 1) Circulating (also called inductive) bearing currents are the only type of bearing currents representing the "classical" mechanism of occurrence. An unbalanced magnetic flux in the stator yoke causes an additional axial flux, which generates a voltage across the shaft ends as described for instance in [3], [4]. Circulating bearing currents are also partially supported by the frequency converter operation. Circulating bearing currents, indicated by ' $a$ ' in Fig. 1, form a closed loop through the rotor, stator, and bearings. 2) Noncirculating (also called capacitive) currents pass through the stray capacitances of an electrical machine. Bearing currents of this type are caused by the frequency converter, and their magnitude depends on the switching of the frequency converter. Noncirculating bearing currents, 
indicated by ' $b$ ' in Fig. 1, flow from the stator winding, and further through a capacitive coupling between the rotor and winding, to the ground. The mechanism of noncirculating bearing currents is described in brief in Section II. 3) Shaft grounding currents [1], [5] may have a "classical" or a frequency-converter-based origin, but the path of such currents goes through the driven load. Grounding currents may occur in the drive system in a case when the driven load has a low-impedance ground connection or if the grounding connection of the motor is broken. Such a parasitic current is flowing through the winding-to-rotor (path $\mathrm{c}$ in Fig. 1) and winding-to-stator (path d in Fig. 1) stray capacitances through the load bearing to the ground. Shaft currents are definitely dangerous for load bearings, and in the case of path $d$ also dangerous for the motor bearing. 4) The stator ground current passes through the winding-to-stator capacitive coupling directly to the ground by means of the grounding terminal of the frame, as shown in path e in Fig. 1. Such a current is not dangerous for the bearings.

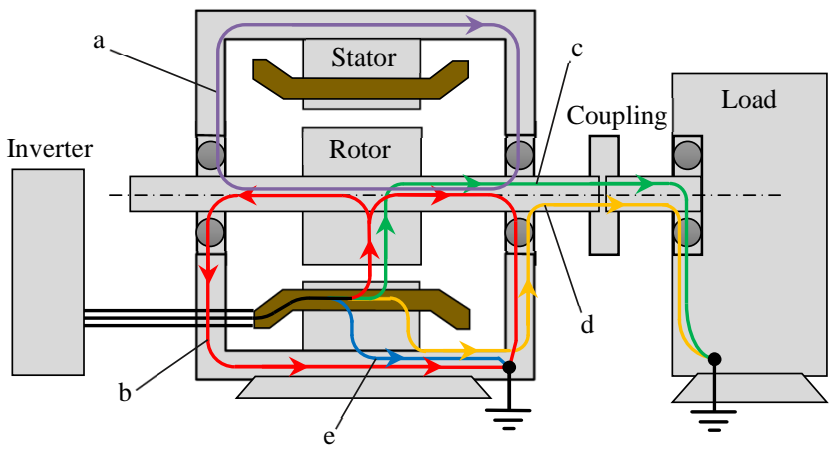

Fig. 1. Schematic of the drive system presented with different stray types of parasitic currents; a: circulating, b: capacitive, c: capacitive through load, d: capacitive winding-stator frame load, and e: capacitive winding-frame.

Moreover, it is known that circulating currents are partly caused by the motor asymmetric geometry and tend to increase with an increasing machine size. Noncirculating currents are generated by common-mode voltage [6].

Different countermeasures aimed to increase the reliability of a drive system and prevent early failure of bearings are presented in the literature. The solutions may contain suppression measures at a very early stage by decreasing the higher voltage harmonics and counteracting the commonmode EMI, when dealing with control algorithms and voltage waveforms at the level of the frequency converter [6], [7]. PWM-based methods to suppress the bearing currents, in the frequency converter use, have been introduced in [8], [9], [10]. In [11], fault detection through shaft signals was studied in order to improve the condition monitoring of rotating machines, and in [12], a method was developed to assess, at the design stage, the risks caused by bearing currents to electrical drive systems. It is also possible to suppress the common-mode voltage and high-frequency harmonics by applying filters and selecting a suitable cable. Alternatively, the solution can be based on partially or completely breaking the stray current circuits by minimizing the machine stray capacitances [13]. Further, there are studies where the influence of currents on the bearing itself is minimized, for instance, by bearing modifications [14] or introducing shaft grounding devices [6], [15], [16]. However, special attention has to be paid to the selection of the countermeasures; if a wrong action is selected, it can even make the situation worse.

The present paper focuses on the noncirculating bearing currents (also called "electric discharge machining" or EDM bearing currents) and precise evaluation of the mitigation technique based on the geometry of the magnetic circuit and the winding. The paper is an extended version of [17]. It introduces the background of the bearing current phenomena and discusses the winding-placement-based approach, which was initially introduced in [17].

The main objective of the work is to verify the preliminary results reported in [17], where the results were obtained for a fictitious machine. The present paper verifies the proposed approach on actual electrical machines by applying their geometries in FEM-based calculations and measuring the BVRs in the laboratory with actual electrical machines.

FEM is frequently applied in the bearing current studies [18] [19] [20].

The study described in the paper concentrates on the winding position options and does not consider other approaches described in [17].

The paper consists of the following sections. In Section II, the circuit mechanism of capacitive currents is explained in brief, some mitigation techniques are discussed, and the theoretical background of the approach based on the stator winding position is given. Section III contains numericalmethod-based calculation results for a single stator slot, with the aim to preliminarily evaluate the proposed approach in a general case. Further, in Section IV, actual electrical machines with known dimensions and parameters are considered. For these machines, a similar FEM-based evaluation of the parasitic capacitances and bearing voltage ratios is presented. The actual measurements and laboratory test results for these machines are also given in Section IV. The remaining sections provide a comparison of the observed results, discussion, and a summary of the study.

\section{NONCIRCULATING BEARING CURRENT CIRCUIT MECHANISM AND MITIGATION OPTIONS}

A typical electric motor design covering the stator, the rotor, and windings represents a number of conductive elements with insulators around them. Such a design may be interpreted as a number of different capacity capacitors, which are formed between isolated conductive parts. Fig. 2 shows a simplified motor design with stray capacitances [1]. 


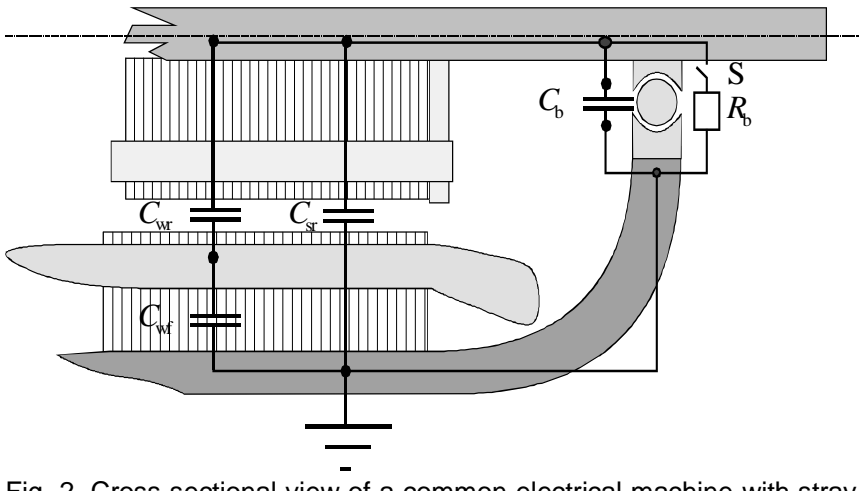

Fig. 2. Cross-sectional view of a common electrical machine with stray capacitances.

During the motor operation, the winding is fed by supply voltage, while the frame of the motor remains grounded. Typically, the rotor assembly is physically connected to the stator through ball or roller bearings. As shown in Fig. 2, the capacitances $C_{\mathrm{wr}}, C_{\mathrm{sr}}$, and $C_{\mathrm{wf}}$ represent stray capacitances between the winding and the rotor, the stator frame and the rotor, and the winding and the stator frame, respectively. The capacitance $C_{\mathrm{b}}$, the resistor $R_{\mathrm{b}}$, and the switch $\mathrm{S}$ represent the bearing behavior when the bearing can be either a conductive or a capacitive element, depending on the instant position of the balls and grease distribution. The switch factors are multiple, complicated, and studied in separate papers; nevertheless, in a simple analysis, the resistive or capacitive state of the bearings is often considered a randomly varying parameter. In most machines, the capacitance $C_{\mathrm{wr}}$ is the one mainly responsible for providing the stray current path from the stator winding to the rotor [1].

As the occurrence of bearing currents is dictated by the relation of the winding-to-rotor and rotor-to-stator capacitances, the mitigation of the bearing current phenomena can be implemented by decreasing the capacitance $C_{\mathrm{wr}}$. A simple plate capacitor has a capacitance of

$$
C=\varepsilon_{\mathrm{r}} \varepsilon_{0} \frac{S}{d}
$$

where $S$ is the surface area of the conductive plates, and $d$ is the distance between the capacitor plates.

Based on (1), varying the distance $d$ between the rotor and the stator gives an inverse dependence on the capacitance and thereby increasing $d$ increases the capacitive reactance. The impedance of a capacitor is increased by reducing the capacitance. Thus, a winding-position-based approach to the suppression of bearing currents is a possible measure to reduce the current by varying the capacitance $C_{\mathrm{wr}}$.

In Section III, this approach will be analyzed by varying the electrical machine design. The dependence of the capacitance $C_{\mathrm{wr}}$ on the stator design options is analyzed numerically. The study covers a typical machine model as a general case as it was suggested in [17] and verifies the results by a comparison of the stray parameters of two actual machines with different winding designs.

\section{DEFINITION OF THE NUMERICAL MODEL AND EVALUATION OF THE WINDING-PLACEMENT-BASED APPROACH FOR A GENERAL CASE}

This section describes the theoretical verification process of the proposed approach. The approach was validated in a general case by FEM calculations. Further (as described in Section IV), the approach was implemented as a full-size testing prototype.

In order to evaluate the effects of varying the stray capacitance, a $15 \mathrm{~kW}$ four-pole 36-slot induction motor was analyzed. The motor dimensions were calculated according to the guidelines given in [1]. The procedure of model building and computation follows the process described in [17].

The value of stray capacitance between the winding and the rotor was evaluated for a single slot opening. The rotor position where the stator slot opening coincides with a rotor tooth was selected for analysis because such a position, in theory, should result in the maximum instantaneous capacitance in comparison with other rotor positions.

The evaluation of the approach is based on the comparison of the winding-to-rotor capacitance of the modified motor with the reference capacitance of the unmodified motor. According to an analytical estimation made in the FEMM 4.2 environment, the winding-to-rotor capacitance of the whole unmodified $15 \mathrm{~kW}$ original motor $C_{\mathrm{wr} \text { ref }}=9.27 \mathrm{pF}$. The "stator-rotor" capacitance for the whole motor $C_{\mathrm{sr}}=221 \mathrm{pF}$. This value was assumed to remain constant, as the slot shape and dimensions were not modified while the distance between the winding and the rotor were varied. The capacitance of a single bearing was assumed to be a common value for several ten-kilowatt motors (the average value of $C_{\mathrm{b}}=0.5 \mathrm{nF}$ ) [21]. The BVR for that case was calculated by using the following equation [22]

$$
B V R=\frac{C_{\mathrm{wr}}}{C_{\mathrm{wr}}+C_{\mathrm{sr}}+2 C_{\mathrm{b}}} .
$$

Because only a single slot of the 36-slot machine was considered, the one-slot capacitances were multiplied before the BVR calculation. As a result of (2), the reference value of the BVR for the unmodified motor $B V R_{\text {ref }}=0.75 \%$ was determined.

Fig. 3 shows the geometry used for the capacitance estimation in the FEMM 4.2 environment. The length of the stator stack lamination was taken as $l=158 \mathrm{~mm}$, and the stator inner diameter was $D_{\mathrm{s}}=160 \mathrm{~mm}$.

In the FEM-based study, where the dependence of the stray capacitance and the bearing voltage ratio on the winding position was analyzed, the distance between the rotor surface and the winding " $h$ " (Fig. 4) was taken as the variable.

Upon the evaluation of the numerical models with several values of $h$, the corresponding capacitance values were determined and the BVRs were calculated. The results are shown in Fig. 5. In order to make the figure more universal, the BVR and the winding-to-rotor capacitances are presented as ratios of the estimated values of $C_{\mathrm{wr}}$ and BVR to the 
reference values $C_{\mathrm{wr} \text { ref, }} B V R_{\text {ref }}$ (i.e., the unmodified motor).

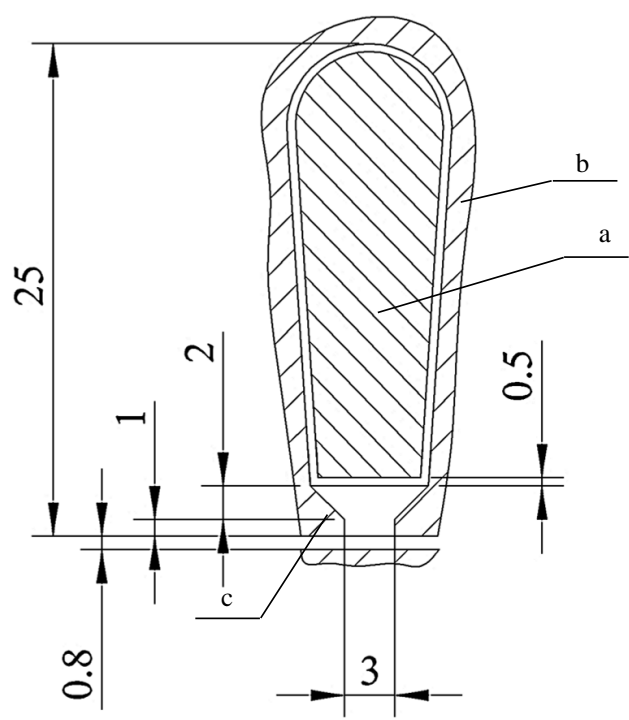

Fig. 3. Original geometry; a) winding, b) stator tooth, and c) rotor. Dimensions in [mm].

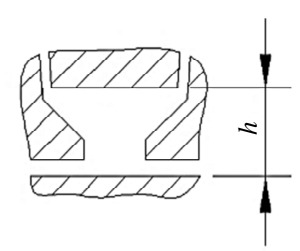

Fig. 4. Winding position, slot opening, and rotor surface. The distance $h$ between the rotor surface and the stator coil.

The main outcome of the study is that the stray capacitance $C_{\mathrm{wr}}$, which causes the EDM bearing currents, decreases when the stator winding is positioned at a larger distance $h$ from the surface of the rotor stack. The BVR, which is considered a main risk factor caused by the bearing currents, shows a similar trend.

Based on this result, it can be seen that placing the stator winding further away from the rotor surface results in reduced capacitive bearing currents.

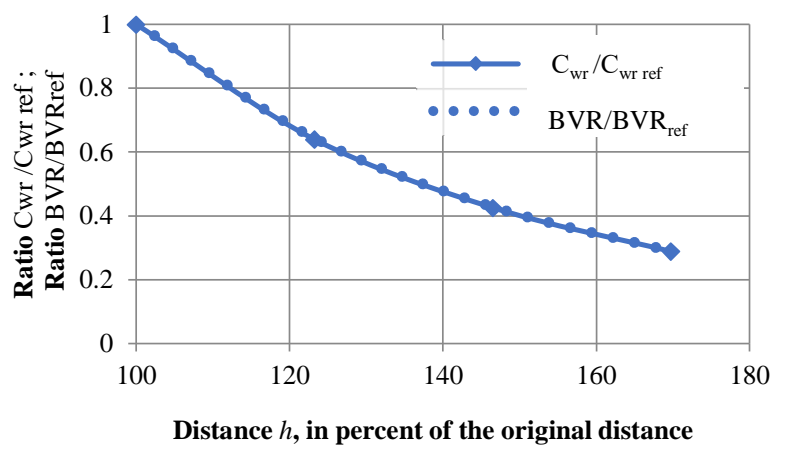

Fig. 5. Dependence of the ratios of the estimated stray capacitances and BVRs to their reference values on the distance $h$ of the stator winding from the rotor surface, given for a single stator slot and applied to the evaluation of the general case.

\section{WINDING-POSITION-BASED APPROACH: VERIFICATION WITH ACTUAL ELECTRICAL MACHINES}

The proposed approach was verified by measuring two 15 $\mathrm{kW}$ 4-pole induction motors in the laboratory. Both motors were produced by ABB and belong to the M3BP 160 MLB 4 series. The first motor, which we will call as "M1", is a regular direct-on-line motor designed for general-purpose applications. The slots and the winding and insulation structure of the motor are shown in Fig. 6. The second machine called "M2" is a machine with special winding insulation for frequency converter supply, equipped with reinforced winding insulation to meet the requirement to operate with an inverter supply, where high amounts of supply voltage and current harmonics are present. The slots and the winding and insulation structure of the special motor are shown in Fig. 7. In the current study, we consider the different wedge insulation thickness as the main difference between the machines. The slot geometries of the motors M1 and M2 are shown in Fig. 8.

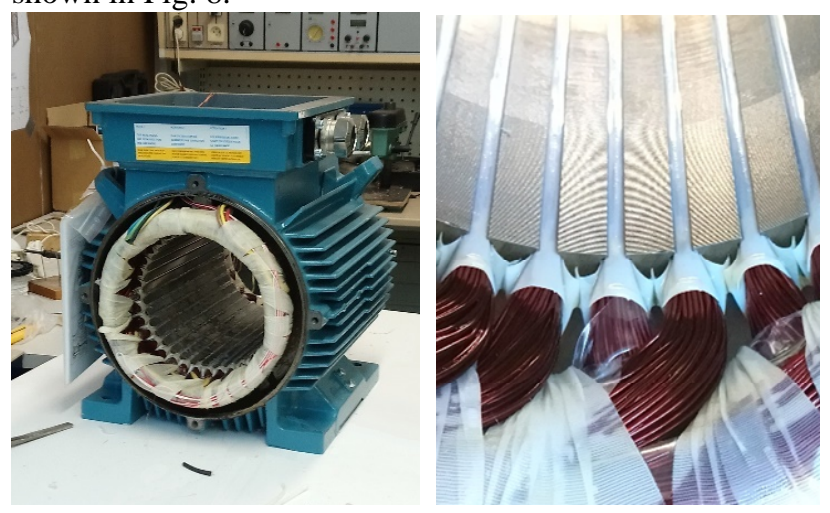

Fig. 6. Regular ABB motor, M1. A general view (left); the slots and the winding and insulation structure (right). There is no slot key in the design and the stator winding protrudes close to the stator inner surface.
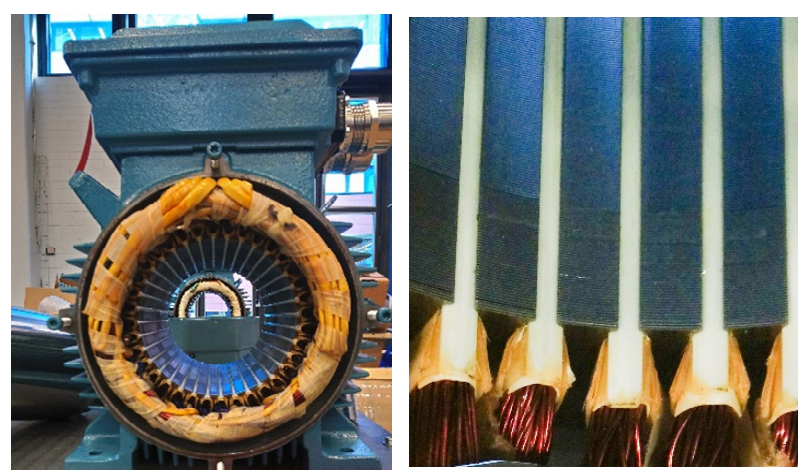

Fig. 7. Converter motor M2 with special winding insulation for frequency converter supply A general view (left); the slots, winding, and insulation structure (right). A strong slot key is used to force the winding far away from the stator inner surface.

\section{A. FEM-based evaluation of the method}

The stray capacitance values and the BVRs were determined analytically by a 2D FEM analysis of the slot geometries from Fig. 8. The figure shows the difference in the distance 
between the winding and the rotor surface for the observed machines. The special motor M2, has additional slot wedge insulation with an extra thickness of $1.2 \mathrm{~mm}$.

The evaluation method follows the technique used in [17] and shown in Section III, and it is applied to evaluate the geometry of an actual machine.

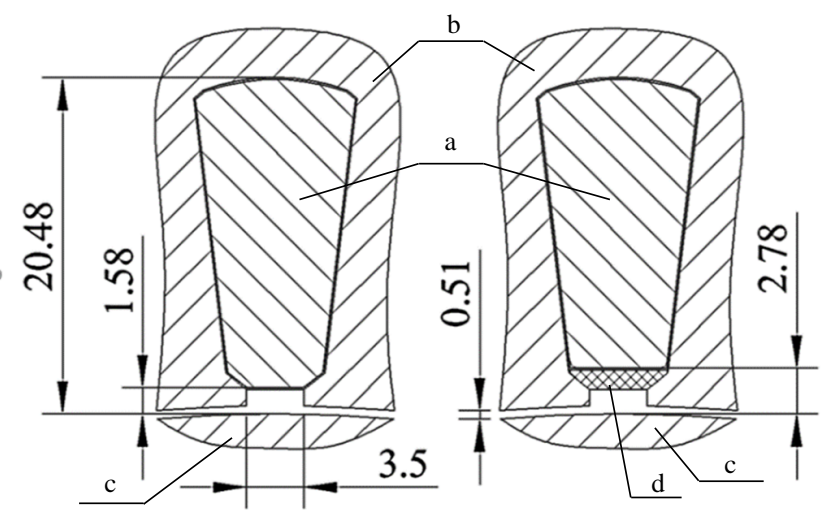

Fig. 8. Slot and wedge insulation geometry of the machines [in $\mathrm{mm}$ ]. A regular $A B B$ motorM1 (left) and a motor variant with special winding insulation for frequency converter supply, M2 (right), where a) winding, b) stator tooth, c) rotor, and d) wedge insulation.

The calculated parasitic capacitances are listed in Table I. However, the BVR is the value commonly used to evaluate the risks caused by bearing currents. Thus, based on the measured capacitances, the BVRs were determined according to (2) and were also included in Table I.

In the calculations, the impact of dielectric permittivity on the BVR was also roughly estimated. The relative permittivity of the wedge material was taken as $\varepsilon_{\mathrm{r}}=4.2$, as it is the average permittivity of most insulating materials. In order to assess the influence of the material permittivity, a material with $\varepsilon_{\mathrm{r}}=1$ was also considered. It was found that the permittivity of the wedge has only a slight effect compared with the wedge thickness.

\section{TABLE I}

ESTIMATED STRAY CAPACITANCES AND BVRS FOR DIFFERENT MACHINE DESIGNS

\begin{tabular}{lcccc}
\hline \hline Motor type & $C_{\mathrm{wr}}, \mathrm{pF}$ & $C_{\mathrm{wf}}, \mathrm{nF}$ & $C_{\mathrm{sr}}, \mathrm{nF}$ & $\begin{array}{c}\mathrm{BVR} \\
\%\end{array}$ \\
\hline Regular motor, M1 & 178 & 171 & 2.06 & 7.86 \\
$\begin{array}{l}\text { Motor with special } \\
\text { winding insulation for } \\
\text { frequency converter } \\
\text { supply, M2, } \varepsilon_{\mathrm{r}}=4.2\end{array}$ & 91.1 & 153 & 2.13 & 4.05 \\
$\begin{array}{l}\text { Motor with special } \\
\text { winding insulation for } \\
\text { frequency converter } \\
\text { supply, M2, } \varepsilon_{\mathrm{r}}=1\end{array}$ & 89.1 & 37.9 & 2.13 & 3.96 \\
\hline \hline
\end{tabular}

\section{B. Laboratory verification of the method}

The bearing current risk in the two electrical machines was evaluated by measurements. The measurement of real capacitances, listed in (2), is difficult as the capacitors cannot be separated from each other in the measurement. Therefore, instead of using (2) and the corresponding capacitance values, the BVR was evaluated as a ratio of voltages

$$
B V R_{\text {measured }}=U_{\mathrm{b}} / U_{\mathrm{cm}}
$$

where $U_{\mathrm{b}}$ is the voltage between the shaft and the grounding point, and $U_{\mathrm{cm}}$ is the common-mode voltage measured between an artificial star point (artificial star point was formed with three $10 \mathrm{M} \Omega$ resistors) and the grounding connection.

For more reliable voltage measurement, both motors were equipped with insulating ceramic bearings. The shaft-toground voltage and the common-mode voltage were measured with Rohde\&Schwarz RT-ZD01 differential probes. The laboratory setup used to measure the BVR of both machines is shown in Fig. 9. The circuit diagram, which illustrates the laboratory setup assembly, is shown in Fig. 10.

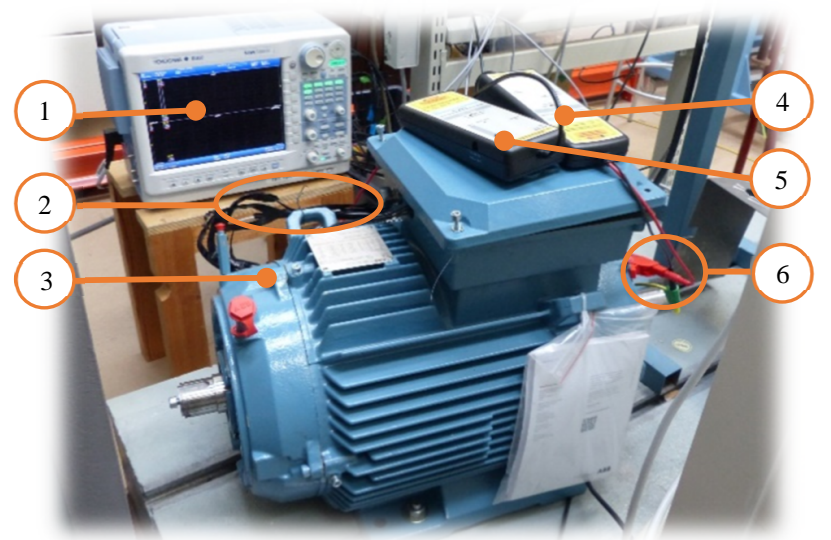

Fig. 9. Overview of the laboratory setup. 1: multi-channel oscilloscope Yokogawa DL850, 2: artificial neutral point connection, 3: the motor under test, 4: Rohde\&Schwarz RT-ZD01 differential probe for shaft voltage measurement, 5: Rohde\&Schwarz RT-ZD01 differential probe for the common-mode voltage measurement, and 6: brush connection to the shaft.

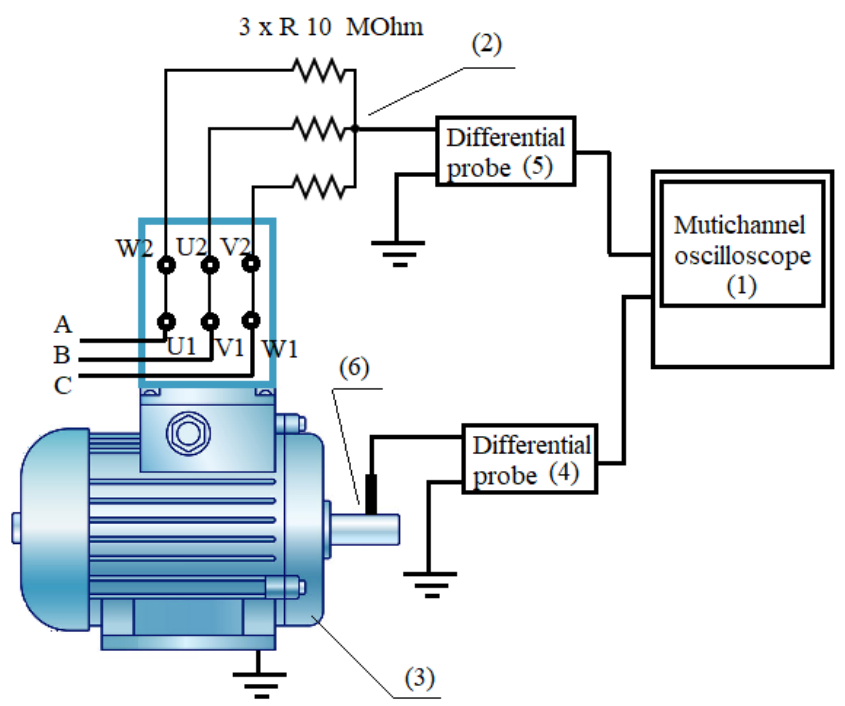

Fig. 10. Circuit diagram of the laboratory setup. 1: multi-channel oscilloscope Yokogawa DL850, 2: artificial neutral point connection, 3: the motor under test, 4: Rohde\&Schwarz RT-ZD01 differential probe for shaft voltage measurement, 5: Rohde\&Schwarz RT-ZD01 differential probe for the common-mode voltage measurement, and 6 : brush connection to the shaft. 
TABLE II

The measurements were performed and stored by a Yokogawa DL850 multichannel oscilloscope. The measurements were carried out as no-load tests, and the motors were supplied by the frequency converter with different supply frequencies at 10, 20, 30, and $40 \mathrm{~Hz}$.

An example of the measured shaft voltage and commonmode voltage waveforms for both motors taken at the supply frequency of $20 \mathrm{~Hz}$ are shown for both motors in Fig. 11 and Fig. 12, respectively. The waveforms taken for 10, 30, and 40 $\mathrm{Hz}$ supply frequencies repeat, in principle, the ones shown for $20 \mathrm{~Hz}$.

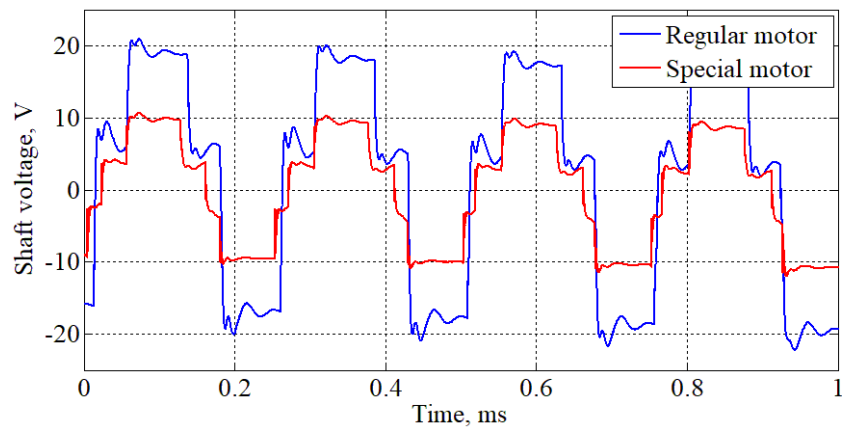

Fig. 11. Measured shaft voltage at the $20 \mathrm{~Hz}$ fundamental PWM supply for the regular and special $15 \mathrm{~kW}$ induction motors.

Fig. 11 shows that the special motor has a clearly lower amplitude of the shaft voltage than the regular motor. Nevertheless, the amplitude of the common-mode voltage remains at the same level for both motors. The shaft voltage and the common-mode voltage were evaluated by the peak-topeak values from the given oscillograms, and they were further used for the BVR calculation by applying (3).

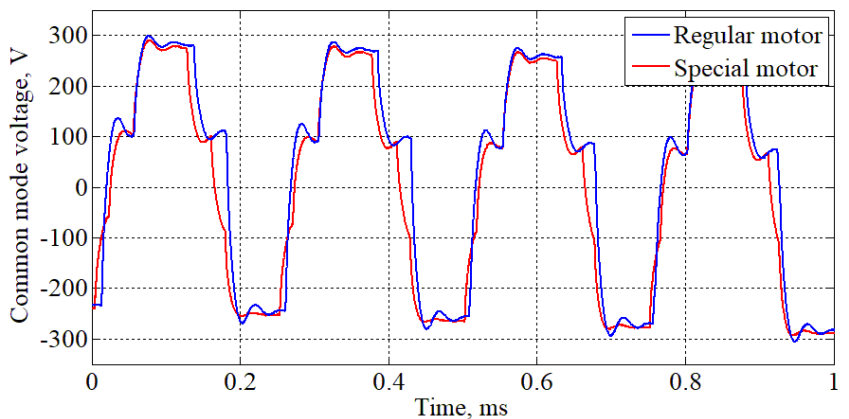

Fig. 12. Measured common-mode voltage at $20 \mathrm{~Hz}$ for the regular and special $15 \mathrm{~kW}$ induction motors.

The low frequency $(150 \mathrm{~Hz})$ component in Figs. 11 and 12 comes from the three-phase diode bridge rectifier and the high-frequency $(4 \mathrm{kHz})$ component comes from the converter switching frequency.

The bearing voltage ratios calculated from the data measured at different frequencies are listed in Table II.

\begin{tabular}{ccc|}
\multicolumn{3}{c}{ MEASURED RAW DATA } \\
\hline \multirow{2}{*}{ Supply frequency, Hz } & \multicolumn{2}{c|}{ BVR (\%), peak-to-peak } \\
& Regular machine, M1 & Special machine, M2 \\
\hline 10 & 7.13 & 3.81 \\
20 & 7.15 & 3.83 \\
30 & 7.13 & 3.78 \\
40 & 7.05 & 3.81 \\
\hline Average value & 7.1 & 3.8 \\
\hline \hline
\end{tabular}

Table II indicates that the motor supply frequency does not have an effect on the BVR. Evidently, it is only related to the common-mode voltage caused by the PWM modulation. Thus, the result obtained by (3) is in agreement with the results. It is thus clear that minimization of $C_{\mathrm{wr}}$ is an efficient way to reduce capacitive bearing currents.

\section{DISCUSSION}

The effect of the stator winding geometry on the stator-torotor stray capacitance and thereby on the BVR was studied and verified.

As it was concluded in [17] and in subsection III-A and Fig. 5, the distance $h$ between the stator winding and the rotor surface has an obvious effect on the $C_{\mathrm{wr}}$ capacitance: a $1 \%$ increase in the distance results in a $1 \%-1.6 \%$ decrease in $C_{\mathrm{wr}}$ in this example. Thus, a simple motor design optimization can be easily applied to reduce the noncirculating bearing currents. An analysis of different winding positions in an actual electrical machine is given in Table III. The table shows the BVRs obtained both from the FEM-based evaluation and the values measured from the actual machines.

TABLE III

COMPARISON OF STRAY CAPACITANCES AND BVR FOR DIFFERENT MACHINES

\begin{tabular}{lcc}
\hline \hline Bearing Voltage Ratio, $B V R[\%]$ & Computed & Measured \\
\hline Regular motor, M1 & 7.86 & 7.09 \\
Special motor, M2 & 4.05 & 3.81 \\
\hline \hline
\end{tabular}

Table III shows that the machine with a larger distance between the rotor surface and the stator winding has a lower BVR. Hence, it can be assumed that the results are in line with the general trend given in Section III and [16]. According to Table I, when the distance between the rotor and the stator winding is increased from 1.58 to $2.78 \mathrm{~mm}$ (as shown in Fig. 8 ), the BVR changes from $7.09 \%-7.86 \%$ to $3.81 \%-4.05 \%$, respectively. Thus, when the stator winding distance to the rotor was changed by $76 \%$, the total change in the BVR turned out to be at the level of $46 \%-48 \%$. When considering the trend of BVR change in relation to the $1 \%$ change in distance, we can conclude that a $1 \%$ increase in the distance results in a BVR reduction of $0.57 \%-0.68 \%$ with this kind of a motor design having semiclosed stator slots.

It is pointed out that in the study of the actual $15 \mathrm{~kW}$ machine, the BVR obtained from the FEM-based computational data and measurements did not differ by more than $11 \%$. This verifies the correctness of the FEM-based approach. Fig. 13 shows the relative dependence of the bearing voltage ratios for the machines under study obtained both by analytical and empirical methods. 


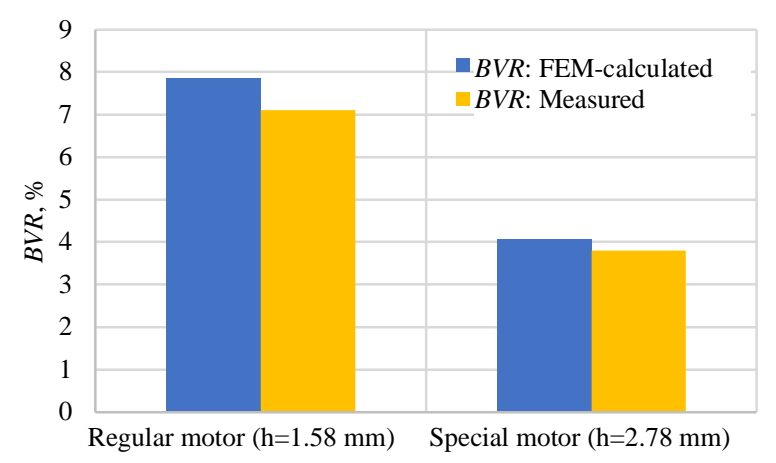

Fig. 13. Relative dependence of the BVRs calculated by the FEM and measured for the regular and special motors, given as a function of the distance of the stator winding from the rotor surface.

Based on the described measurements, we can state that the approach of varying the winding position was verified in practice and can be considered a relevant and effective method to suppress the noncirculating bearing currents.

The method uses a very straightforward physical principle of reducing the capacitance. It is expected to be relevant in different power ranges and in machines with varying designs. The capacitances were found to be dependent on the geometry of the slots and it is fair to assume that e.g. a load change, varying pole number and different supply or operational conditions will not change the capacitance value, and thus, the BVR behavior trend remains similar as presented in this work.

Together with the thickness of the wedge insulation, the influence of the material relative permittivity was briefly evaluated. In Table I one may see that the reduction of the wedge permittivity from $\varepsilon_{\mathrm{r}}=4.2$ down to $\varepsilon_{\mathrm{r}}=1$ will give a BVR reduction in the order of just $0.1 \%$, which is insignificant compared to the BVR change, obtained when the wedges were introduced. This allows the authors to conclude that the material relative permittivity does not play a key role in the presented approach, and its influence is negligibly small.

However, it should be borne in mind that the present study only deals with the stator slot part and does not affect the endwinding capacitances. Because in small-scale machines the stray capacitance between the end winding and the rotor can be comparable with the capacitance coming from the slot, the adaptation of the method for machines of different sizes and scaling features should be considered for instance as proposed in [23]. Moreover, the configuration of the end-windings and the length of the windings overhang may vary between the machines with different number of pole pairs, slots, or a number of slots per pole and phase. Taking into account the fact, that the influence of the end-winding was left out from the scope of the current study, the effectiveness of the presented approach is expected to slightly decrease in machines with a large end winding.

Although the presented approach aimed to increase the reliability of the electrical machine, the drawbacks of the proposed method should be mentioned as well.

The introduction of an additional layer into the stator slots reduces the space for the copper winding. In other words, the copper space factor is supposed to be reduced when the technique presented is applied. In the case of two reviewed machines, the slot's effective cross-sectional area, dedicated for the stator winding, was $142.3 \mathrm{~mm}^{2}$ and $136.4 \mathrm{~mm}^{2}$ in the original and the special machine respectively. I.e., the area reduction, and thus, copper space factor decrease, turns to be $4.15 \%$. As a result of reducing the overall cross-sectional area of the conductors, the current density in the winding is also supposed to be increased accordingly. Such a change may be considered negligible.

Thanks to the simplicity of the proposed approach and utilization of regular materials (glass-fibre slot keys), the cost of the implementation is supposed to be minimal. In case of producing a new machine, only the cost of materials and minor extra work should be considered. An existing machine modification obviously is less practical because of the complexity and high cost of the rewinding work. However, this is in principle possible and can be done in exceptional cases e.g. if the winding has to be replaced as a result of insulation failure.

\section{CONCLUSION}

The problem of noncirculating bearing currents was addressed and mitigation options were suggested based on the special motor geometry design and verified by analyzing actual motors both in theory and in practice. The theoretical background and a numerical-method-based investigation of the proposed technique were provided and applied in the study. The obtained results show that modifying the stator winding position seems to be an effective way to reduce the stray capacitance $C_{\mathrm{wr}}$ and the bearing voltage ratio (BVR). If used at the motor design stage, the presented approach allows producing more reliable machines that will suffer less from the noncirculating bearing currents. The analysis of the motors shows that for a frequency converter supply it is recommended to purchase a specially designed machine with an increased insulation thickness and a higher stator winding distance from the rotor. The use of such a machine gives, on average, a $50 \%$ reduction in the bearing voltage ratio and is an effective solution for mitigating capacitive bearing currents. Despite the fact that the influence of the end-windings is not affected by the approach, and the slot space factor may slightly suffer, the BVR reduction achieved by the method becomes significant and makes the method worth considering for industrial applications when trying to mitigate bearing currents with minimum design changes in the motor.

\section{REFERENCES}

[1] J. Pyrhönen, V. Hrabovcova and R. Scott Semken, Electrical Machine Drives Control: An Introduction, John Wiley \& Sons Ltd, ch. 13, 2016.

[2] Philip M. Gonski, Diagnosing \& Understanding Motor Bearing Currents / Keystone Engineering Group, Inc. - 2012 [Online]. Available: - https://www.ecmweb.com/motors/diagnosingunderstanding-motor-bearing-currents.

[3] A. Muetze and A. Binder, "Calculation of Circulating Bearing Currents in Machines of Inverter-Based Drive Systems," in IEEE Transactions on Industrial Electronics, vol. 54, no. 2, pp. 932-938, April 2007.

[4] T. Plazenet, T. Boileau, C. Caironi and B. Nahid-Mobarakeh, "An overview of shaft voltages and bearing currents in rotating machines," 2016 IEEE Industry Applications Society Annual Meeting, Portland, OR, 2016, pp. 1-8. 
[5] I. Boldea and Syed A. Nasar, Electric Drives, 2 nd edition, CRC Press, ch. 13, 2006.

[6] ABB drives, "Bearing currents in modern AC drive systems, Technical guide No. 5," 2011. [Online]. Available: https://library.e.abb.com/public/8c253c2417ed0238c125788f003cca8e/ ABB_Technical_guide_No5_RevC.pdf.

[7] A. Muetze, "Scaling Issues for Common-Mode Chokes to Mitigate Ground Currents in Inverter-Based Drive Systems," IEEE Transactions on Industry Applications, vol. 45, no. 1, pp. 286-294, Jan.-Feb. 2009.

[8] S. Karugaba, A. Muetze and O. Ojo, "On the Common-Mode Voltage in Multilevel Multiphase Single- and Double-Ended Diode-Clamped Voltage-Source Inverter Systems," in IEEE Transactions on Industry Applications, vol. 48, no. 6, pp. 2079-2091, Nov.-Dec. 2012

[9] Haoran Zhang, A. Von Jouanne, Shaoan Dai, A. K. Wallace and Fei Wang, "Multilevel inverter modulation schemes to eliminate commonmode voltages," in IEEE Transactions on Industry Applications, vol. 36, no. 6, pp. 1645-1653, Nov.-Dec. 2000.

[10] C. Bharatiraja, R. Selvaraj, T. R. Chelliah, J. L. Munda, M. Tariq and A. I. Maswood, "Design and Implementation of Fourth Arm for Elimination of Bearing Current in NPC-MLI-Fed Induction Motor Drive," in IEEE Transactions on Industry Applications, vol. 54.

[11] T. Plazenet, T. Boileau, C. Caironi and B. Nahid-Mobarakeh, "A Comprehensive Study on Shaft Voltages and Bearing Currents in Rotating Machines," in IEEE Transactions on Industry Applications, vol. 54, no. 4, pp. 3749-3759, July-Aug. 2018.

[12] J. Ahola, A. Muetze, M. Niemelä and A. Romanenko, "NormalizationBased Approach to Electric Motor BVR Related Capacitances Computation," in IEEE Transactions on Industry Applications, vol. 55, no. 3, pp. 2770-2780, May-June 2019.

[13] David B. Hyypio, "Dynamoelectric machines with shaft voltage prevention method and structure, " US patent 5821652 A, Oct. 13, 1998.

[14] A. Muetze and A. Binder, "Experimental evaluation of mitigation techniques for bearing currents in inverter-supplied drive-systems investigations on induction motors up to $500 \mathrm{~kW}, "$ in Electric Machines and Drives Conference 2003. IEMDC'03. IEEE International, 2003, pp. 1859-1865 vol.3.

[15] A. Muetze and H. W. Oh, "Application of Static Charge Dissipation to Mitigate Electric Discharge Bearing Currents," IEEE Transactions on Industry Applications, vol. 44, no. 1, pp. 135-143, Jan.-feb. 2008.

[16] H. W. Oh and A. Willwerth, "Shaft Grounding - A Solution to Motor Bearing Currents," ASHRAE Transactions Vol. 114, Part 2, pp. 246251, 2008.

[17] K. Vostrov, J. Pyrhönen, J. Ahola and M. Niemelä, "Non-circulating Bearing Currents Mitigation Approach Based on Machine Stator Design Options," 2018 XIII International Conference on Electrical Machines (ICEM), Alexandroupoli, 2018, pp. 866-872.

[18] M. Jaritz, C. Jaeger, M. Bucher, J. Smajic, D. Vukovic and S. Blume, "An Improved Model for Circulating Bearing Currents in Inverter-Fed AC Machines," 2019 IEEE International Conference on Industrial Technology (ICIT), Melbourne, Australia, 2019, pp. 225-230.

[19] C. Jaeger, I. Grinbaum and J. Smajic, "Numerical simulation and measurement of common-mode and circulating bearing currents," 2016 XXII International Conference on Electrical Machines (ICEM), Lausanne, 2016, pp. 486-491.

[20] M. Schuster, D. Masendorf and A. Binder, "Two PMSMs and the influence of their geometry on common-mode bearing currents," 2016 XXII International Conference on Electrical Machines (ICEM), Lausanne, 2016, pp. 2126-2132.

[21] A. Romanenko, J. Ahola, A. Muetze and V. Niskanen, "Study of incipient bearing damage monitoring in variable-speed drive systems," in 2014 16th European Conference on Power Electronics and Applications, Lappeenranta, 2014, pp. 1-10

[22] A. Muetze and A. Binder, "Calculation of Motor Capacitances for Prediction of the Voltage Across the Bearings in Machines of InverterBased Drive Systems," IEEE Transactions on Industry Applications, vol. 43, no. 3, pp. 665-672, May-june 2007.
[23] K. Vostrov, J. Pyrhönen and J. Ahola, "The Role of End-Winding in Building Up Parasitic Capacitances in Induction Motors," 2019 IEEE International Electric Machines \& Drives Conference (IEMDC), San Diego, CA, USA, 2019, pp. 154-159.

\section{BIOGRA}

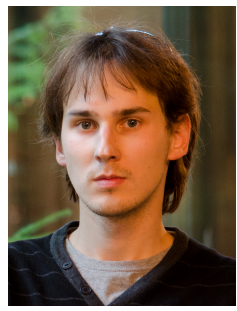

Konstantin Vostrov was born in Leningrad, Russia, in 1991. He received the B.Sc degree in the field of Electrical Engineering, Electromechanics and Electrotechnology from Peter the Great St. Petersburg Polytechnic University in 2014, and the double-degree M.Sc from the Peter the Great St. Petersburg Polytechnic University in 2015 and Lappeenranta University of Technology in 2016 . He is currently a doctoral student at Lappeenranta University of Technology and his major research interest at the current time is the investigation of the bearing currents phenomena in electrical drives and development of the appropriate countermeasures.

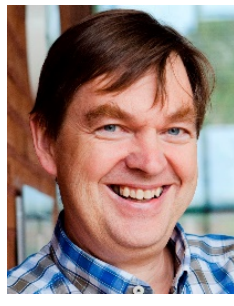

Juha Pyrhönen (M’06), was born in 1957 in Kuusankoski, Finland, received the Doctor of Science (D.Sc.) degree in Electrical Engineering from Lappeenranta University of Technology (LUT), Finland in 1991. He became an Associate Professor of Electrical Engineering at LUT in 1993 and a Professor of Electrical Machines and Drives in 1997. He is engaged in research and development of electric motors and electric drives. His current interests include different synchronous machines and drives, induction motors and drives and solid-rotor high-speed induction machines and drives.

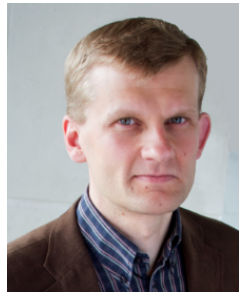

Markku Niemelä received the B.Sc. degree in electrical engineering from Helsinki Institute of Technology, Helsinki, Finland, in 1990 and the M.Sc. and D.Sc. degrees in technology from Lappeenranta University of Technology (LUT), Lappeenranta, Finland, in 1995 and 1999, respectively. $\mathrm{He}$ is currently a Senior Researcher with the Carelian Drives and Motor Centre, LUT. His current interests include motion control, control of line converters, and energy efficiency of electric drives.

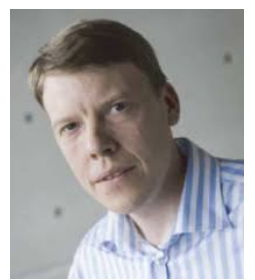

Jero Ahola was born in Lappeenranta, Finland, in 1974. He received the M.Sc and D.Sc. degrees in electrical engineering from Lappeenranta University of Technology (LUT), Lappeenranta, Finland, in 1999 and 2003, respectively. He is currently a Professor of Energy Efficiency in Electrical Systems and Proactive Maintenance of Electrical Equipment with the Department of Electrical Engineering, LUT. His research interests include energy efficiency in electrical motor driven systems, solar photovoltaic systems, power-to-X, and power-line communication in the motor cables of variable speed electric drives.

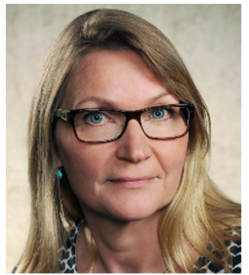

Pia Lindh (M'04) born in Helsinki in 1969, received her M.Sc. degree in energy technology in 1998 and her D.Sc. degree in electrical engineering (Technology) in 2004 from Lappeenranta University of Technology (LUT), Lappeenranta, Finland. She is currently serving as an associate professor at the Department of Electrical Engineering in LUT Energy, Lappeenranta, where she is engaged in teaching and research of electric motors and electric drives. 